\title{
Convocação de espaços afetivos pela fotografia contemporânea
}

\author{
Ana Paula Barbosa Ferreira Ottoni ${ }^{1}$ \\ DOI 10.20396/eha.vil4.3445
}

A investigação da experiência estética advinda do encontro com um determinado recorte imagético localizado na história da fotografia contemporânea é o propósito deste trabalho. A particularidade das imagens que despertaram a iniciar esta pesquisa não está relacionada ao ponto de vista técnico da fotografia, visto que algumas guardam, inclusive, proximidade à uma produção mais corriqueira. Descritivamente, de modo geral, são fotografias de ambientes internos ou externos do repertório cotidiano urbano.

Imagens triviais que, exatamente pela sua frugalidade, operam um jogo de ambiguidades no que se refere ao seu caráter técnico e narrativo visível e sua afetividade pulsante. Descondicionam o olhar e indagam, de imediato, sobre o que pode ou deve ser visto, agenciam espaços afetivos, aguçam os sentidos e tiram das sombras o que passa.

De fato, o que via era representação, estava visto, entendido. Entretanto, o entendido era apenas o começo. E, assim sendo, tal premissa foi direcionadora da investigação: não embaçar a imagem em busca do mistério, contudo, sem reduzir seus possíveis atravessamentos culturais e sensíveis.

André Rouillé observa muito bem a busca da fotografia artística por uma diferenciação da chave documental apostando em recursos exagerados e fuga do "realismo plano e a trivial realidade das coisas e do mundo"2, patinando em seus resultados ao se distanciar do seu "valor mágico"3. $\mathrm{O}$ autor, entende que os fotógrafos, em determinado momento histórico, acabavam por utilizar processos anacrônicos em busca de similitudes com a pintura, movidos por uma pretensão artística. Desse modo, Rouillé utiliza o conceito de Gilles Deleuze e Felix Guarttari relativo à desterritoriali-

\footnotetext{
1 Universidade de Brasília, bacharela em Teoria, Crítica e História da Arte.

2 ROUILLÉ, 1998, p. 307.

Cf. BEN]AMIN, 1994, p. 94.

4 Trechos relativos aos conceitos de desterritorialização e reterritorialização desenvolvidos por Gilles Deleuze e Félix Guattari na obra "Mil platôs - capitalismo e esquizofrenia": "Temos que pensar a desterritorialização como uma potência perfeitamente positiva, que possui seus graus e seus limiares (epistratos) e que é sempre relativa, tendo um reverso, uma complementaridade na reterritorialização. Um organismo desterritorializado em relação ao exterior se reterritorializa necessariamente nos meios interiores." (1997, vol.1, p.68)
} 
zação e territorialização para entender o deslocamento da fotografia como documento:

Para falar como Deleuze, eu diria que a fotografia artística "desterritorializa" a fotografia documentária, que ela e a conduz para fora do território da estrita duplicação do real e da pura utilidade, mas que ela a "reterritorializa" em uma acepção passadista e arcaica da arte. $^{5}$

No entanto, neste trabalho, opto por aplicar o conceito de desterritorialização e reterritorialização, como um lugar de possibilidades outras, não somente como um recalque da natureza da fotografia. Considero que as imagens, as quais serão apresentadas, advindas do olhar fotográfico em determinadas espacialidades e seus deslocamentos como matéria, olhadas novamente, ainda que capturadas sem opacidades ou pirotecnias do desejo de distanciamento do registro documental, também são desterritorializadas a partir do recorte do fotógrafo, pelos suportes nos quais são exibidas ou impressas e, finalmente, reterritorializadas não somente pela sua atual localização física, mas também pelo modo como são expostas e pelo tempo histórico no qual estão sendo revistas.

A definição de Charlortte Cotton para fotografia contemporânea artística em sua obra "Fotografia como arte contemporânea", a qual agrupa obras de 250 fotógrafos, sendo ela curadora e diretora artística de instituições museais, me parece pertinente e norteadora para delimitar esse embaralhado universo de possibilidades de produção:

Cada fotógrafo aqui representado assume o compromisso de dar sua contribuição ao espaço físico e intelectual da cultura. Numa interpretação das mais literais, isso significa que todos os fotógrafos que estão neste livro criam obras destinadas a serem expostas nas paredes de galerias e nas páginas dos livros de arte. ${ }^{6}$

As imagens que serão exibidas são algumas das que, enquanto observadora, me afetaram não somente pela estrita afeição, mas sim, pelo convite a agir, operar e a produzir, feito por elas. Ao observar tais imagens me pergunto: o que pode ou deve ser fotografado? Ao mesmo tempo, apenas olho e vejo um espaço afetivo, que parece tão displicente, de relance, mas que na verdade foi deliberadamente conquistado. Quem sabe, um lugar particular para o fotógrafo que o impele ao recorte.

Georges Didi-Huberman classifica como "leitura regozijante"7 um texto em que, segundo ele, Georg Simmel "reverte a perspectiva platônica da evidência sensível", na qual o inapreensível esta-

\footnotetext{
5 ROUILLÉ, 1998, p. 307.

6 COTTON, 2013, p. 9.

7 Cf. DIDI-HUBERMAN, 2018, p. 135.

8 Ibid.
} 
ria para além da imagem, citando o seguinte trecho:

O que está para além do conhecimento não é o que está detrás da imagem das coisas, o obscuro, o em-si, o inapreensível - mas, ao inverso, é justamente o imediato, a imagem plenamente sensível, a superfície das coisas virada para nós. Não é além, mas aquém da ciência que o conhecimento para. O fato de não exprimirmos em conceitos o que justamente vemos, tocamos, vivemos de não podermos fazê-lo entrar tale quale nas formas do conhecimento - nós o explicamos de maneira totalmente errônea: como se justamente os conteúdos dessas formas escondessem algo misterioso e irreconhecível ${ }^{9}$.

Ao mesmo tempo, Ronaldo Entler chama atenção para a aparente simplicidade deste tipo de resultado imagético no seguinte trecho:

Mesmo que tenha menor preocupação em demonstrar seu estatuto de construção cultural, essa fotografia que sobrevive e que negocia sua presença no contexto da arte contemporânea não pode ser chamada de ingênua: Ela não deixa de estar rodeada por discursos sofisticados, às vezes mais acadêmicos, às vezes mais poéticos, mas que sempre contrastam com sua simplicidade formal. ${ }^{10}$

Tratam-se de abordagens distintas. A primeira, uma crítica acerca do conhecimento produzido sobre a imagem, quase que negando a sua própria existência enquanto objeto visível. Já a segunda, alerta para uma suposta ingenuidade no conteúdo de parcela das produções fotográficas no âmbito da arte contemporânea. Ponderações pelas quais me guiarei.

Me posiciono como uma investigadora híbrida, valendo-me do suporte teórico dos pesquisadores e das fotografias que analiso e faço. Por isso, entendo que o que deve ser ou não fotografado está estreitamente relacionado ao que deve ou não ser exposto já que, no segundo caso, chegará ao observador. Em ambos pontos de vista, a questão é o cotidiano como tema de interesse na arte contemporânea. Cotton toca a questão afirmando que "a esse respeito, os artistas contemporâneos decidiram que, graças a um ponto de vista sensibilizado e subjetivo, tudo que há no mundo real é um tema em potencial"11.

Mas como se fazem determinadas escolhas dentro do universo cotidiano? Ao observar as imagens a seguir notaremos que não se aponta simplesmente a câmera para qualquer direção e aciona-se o botão de disparo, não obstante temas ou narrativas serem corriqueiros. O fato é que o aparente relaxamento da imagem, muito provavelmente, reivindicou um preciso delineamento

\footnotetext{
9 DIDI-HUBERMAN, 2018, p. 135

10 ENTLER, 2011, p. 74

11 COTTON, 2013, p. 10
} 
do recorte e alguns disparos além do que é mostrado. Analogamente, em argumentação sobre a mítica do instantâneo como sendo aquele momento mágico no qual o fotógrafo em um só lance vê e captura uma impressionante imagem, tanto nos seus aspectos técnicos, quanto nos poéticos ou estéticos, tal como no instante decisivo de Cartier-Breson ou, ainda, na street photography, Ronaldo Entler entende como uma visão limitadora sobre o fotógrafo:

\begin{abstract}
Maneira simplista de pensar a fotografia, essa ideia cai por terra quando vemos a folha de contato de um fotógrafo: nele, percebemos que a presença do fotógrafo no local foi planejada, que cena foi antevista, mapeada, cercada, que a imagem foi testada, refeita, negociada, e posteriormente editada. [...] Mas, ao isolar e supervalorizar o momento da tomada, cria-se a ideia de que a imagem surge como uma comunhão repentina entre o ol har e o mundo. Essa mística serve também para reintroduzir a ideia de "dom" numa produção que tantas vezes foi entendida como mecânica, desprovida de espiritualidade."12
\end{abstract}

Ou seja, o que veremos nas fotografias não nos dá certeza sobre o modo ou a razão de terem sido realizadas, os quais exerceriam certo magnetismo, como o que ocorria com a street photography, dos anos 70, mas nos oferece questões sobre escolhas temáticas e espaciais. Para Susan Sontag, o fazer fotografia é como um outro modo de ver tudo ao nosso redor:

Essa insaciabilidade do ol ho que fotografa altera as condições do confinamento na caverna: o nosso mundo. Ao nos ensinar um novo código visual, as fotos modificam e ampliam nossas ideias sobre o que vale a pena olhar e sobre o que temos o direito de observar. Constituem uma gramática e, mais importante ainda, uma ética do ver. Por fim, o resultado mais extraordinário da atividade fotográfica é nos dar a sensação de que podemos reter o mundo inteiro em nossa cabeça — como uma antologia de imagens. ${ }^{13}$

Neste sentido, o resultado imagético realizado por Nigel Shafran (figura 1), fotógrafo e artista britânico, é preciso. Observar o trabalho de Shafran é, inicialmente, questionar escolhas. No entanto, no momento seguinte, é perceber o quanto eventos que partem de um recorte particular do cotidiano do fotógrafo compõem uma espécie de diário, que é tão comum ao modo de vida urbano.

A imagem, a qual pertence a série "Ruthbook", exibe, ao centro, uma caixa de costura empiIhada sobre um pequeno banco de madeira posicionado sobre mesinhas de plástico maiores. No entanto, no espaço escolhido pelo fotógrafo há alguns objetos e situações que remetem a processos em andamento. Ao fundo, uma janela trocada sem acabamento, um tubo de cola grande no lado 
esquerdo, uma caixa com pedras e uma ferramenta ao lado direito que parecem não pertencer ao cômodo. A cortina amarrotada dá a impressão de haver sido recém-instalada. Alguns restos de madeira no chão, próximos ao pé da mesa da televisão.

A cena, embora perfeitamente controlada e, ao mesmo tempo casual, indica um ambiente em transformação. A imagem que, em um primeiro momento se mostra crua e estática, revela outras camadas de percepção sem abandonar sua simplicidade temática. A potência afetiva deste trabalho se evidencia nas suas ambiguidades. O controle da luz, o corte aparentemente displicente, mas que seleciona cuidadosamente o que deve ser compartilhado do seu diário íntimo e doméstico, aliado a uma certa incoerência do conjunto de objetos que compõem o cômodo são cuidadosamente delineados pelo fotógrafo.

A imagem funciona como relato, que acontece sempre em relação ao ponto de vista do fotógrafo e, neste caso, sobre o ambiente do próprio autor. Para Certeau, os relatos têm a capacidade de elaborar ou desfazer espaços. Ele diferencia espaços e lugares do seguinte modo:

[...] lugar é a ordem (seja qual for) segundo a qual se distribuem elementos nas relações de coexistência. [...] Implica uma indicação de estabilidade. Existe espaço sempre que se tomam vetores de direção, quantidades de velocidade e a variável do tempo. É de certo modo animado pelo conjunto de movimentos que aí se desdobram. ${ }^{14}$

Na fotografia do cotidiano vemos com clareza a proposição de Certeau, na migração de interesses de conteúdo em conjunto com a prática espacial onde só havia lugares ou até mesmo não -lugares ${ }^{15}$.

Nesta chave percebo parte da produção de Stephen Shore, fotógrafo norte-americano, como provocadora e bem-humorada. Embora a fotografia (figura 2) seja de 1971, período anterior à supermodernidade discutida por Augé, vemos na imagem uma mesa com alguns objetos e um lanche, os quais poderiam estar localizados, à época, em outros não-lugares. Não há qualquer particularidade em sua materialidade. Entretanto, Shore parece virar a mesa em nossa direção para nos mostrar sua superfície em relação ao restante do espaço, expediente evidenciado pelo seu enquadramento propositadamente enviesado. No centro, um prato com o sanduíche, mas Shore opta por nomear a fotografia de Granite, uma referência ao material da mesa que imita a pedra que

\footnotetext{
14 CERTEAU, 1998, p. 201

15 Em sua obra "Não-lugares: Introdução a uma antropologia da supermodernidade", Marc Augé explora a relação da sociedade com o que ele definiu como não-lugar. Em linhas gerais o conceito engloba locais padronizados que podem ser encontrados em diferentes culturas, nos quais se espera um mesmo tipo de comportamento com regras gerais bem definidas e que despersonalizam os frequentadores. Em geral são lugares de passagem ou permanência reduzida.
} 


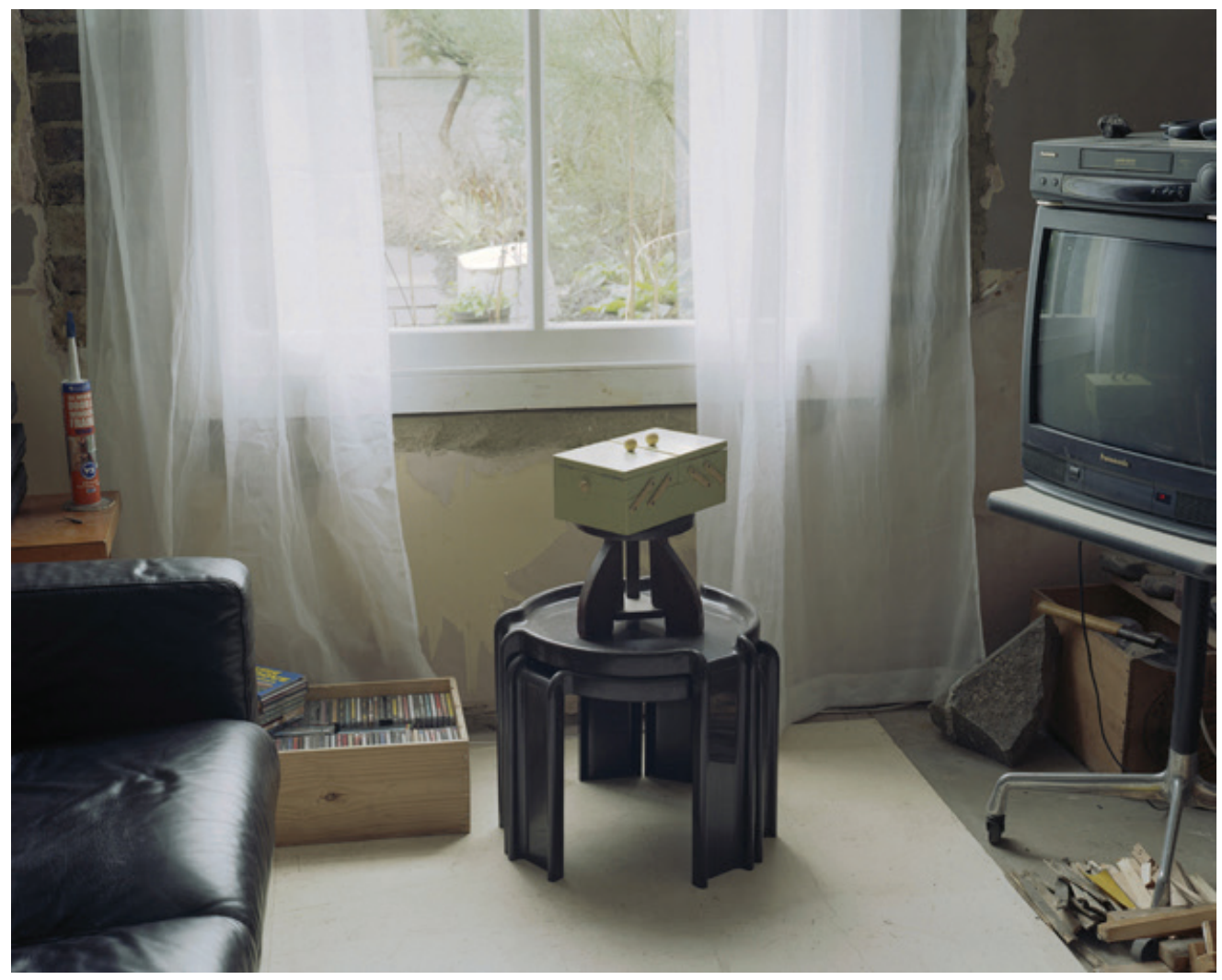

[Figura 1] Nigel Shafran. Ruthbook, 1992-2004.

Disponível em:<http://nigelshafran.com/category/ruthbook-1992-2004/page/15/> Acesso em: 20/06/2019.

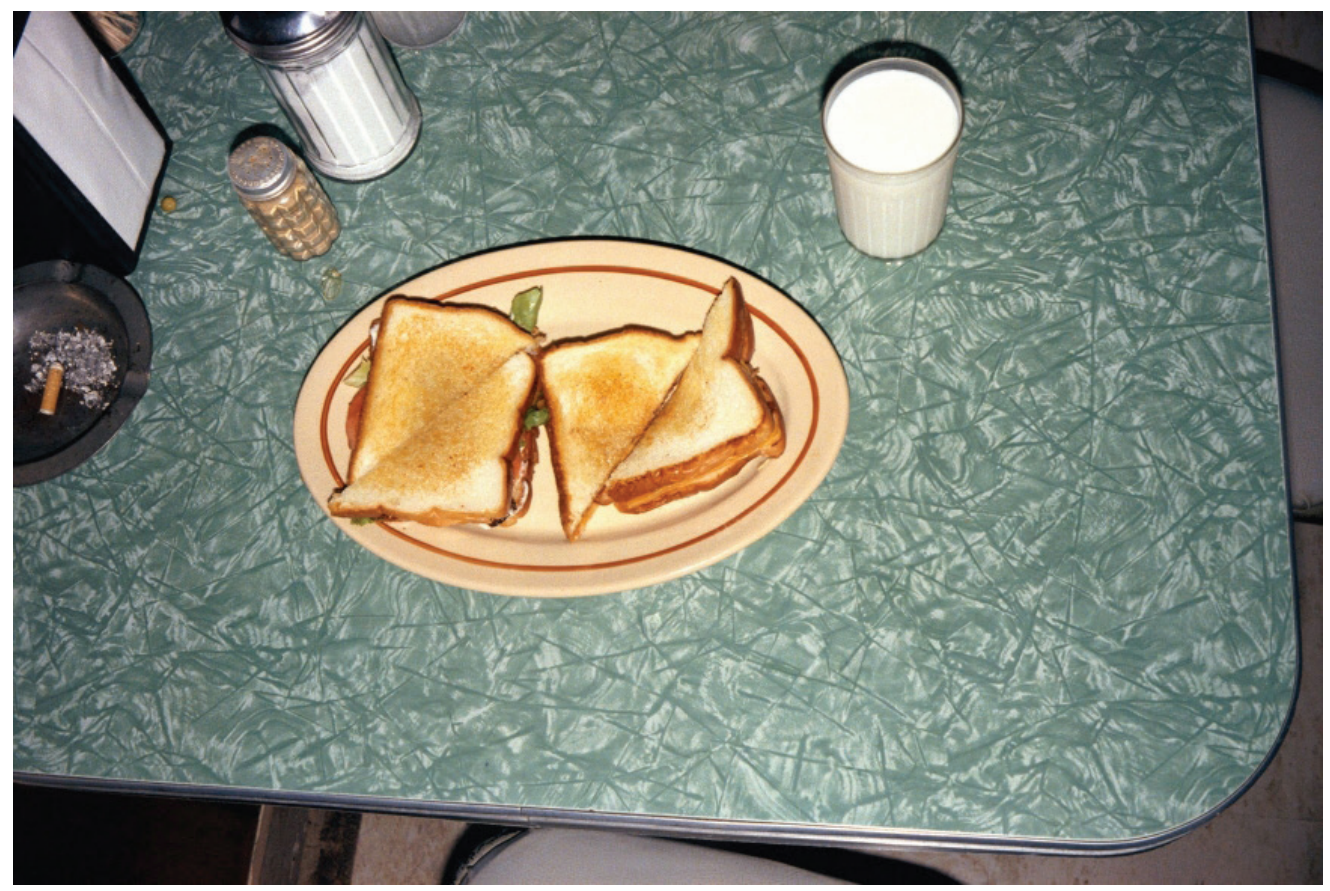

[Figura 2] Stephen Shore. Granite, Oklahoma, 1972.

Impressão colorida cromogênica. 12.7 x $19.1 \mathrm{~cm}$. Tate Gallery, Londres, Reino Unido. Disponível em:https:// www.tate.org.uk/art/artworks/shore-granite-oklahoma-july-1972-p81327>. Acesso em: 20/06/2019. 
dá nome à pequenina cidade de Oklahoma, na qual o espaço foi fotografado. E, trabalhando nesta imagem diante de um conteúdo tão banal, Shore afeta com sua atenção aguçada ao que permeia seu campo de visão e, ao mesmo tempo, nos introduz ao seu divertido esquema.

O deslocamento de espacialidades inseridas no cotidiano é ponto crucial da fotografia artística contemporânea. Roland Barthes amplifica a análise acerca da imagem reproduzida pela fotografia, decretando a morte do índice fora da dela, nomeando o deslocamento possível de "o retorno do morto", nos remetendo também à posse simbólica do impossível:

[...] eu chamaria de Spectrum da Fotografia, porque essa palavra mantém, através de sua raiz, uma relação como "espetáculo" e a ele acrescenta essa coisa um pouco terrível que há em toda fotografia: o retorno do morto. ${ }^{16}$

Para além dos fotógrafos viajantes, exploradores, que fotografaram, e os que continuam saciando a curiosidade da sociedade desde o início do século XX (haja vista a quantidade de sites e programas sobre viagens), o deslocamento de espacialidades proporcionado pela fotografia atua de modo extremamente possante quando realizado pela via do cotidiano.

A transparência aparente deste recorte, bem como seu objeto, aproximam, também, por identificação. De acordo com Hans Ulrich Gumbretch, a experiência estética é preenchida por "sentimentos íntimos, as impressões e as imagens produzidas na nossa consciência"17.

Ao observar uma fotografia em um espaço expositivo ou, ainda, pela experimentação de fotografar temas cotidianos, nossa visão sobre o banal é modificada. A fotografia se instaura em nós como um lembrete de que o que está à nossa volta tem um potencial para além do que estamos habituados a captar e estabelecer diálogo.

As irrupções poéticas no cotidiano ou, ainda, segundo Gumbretch, as "pequenas crises"18, são desencadeadoras de experiências estéticas, já que "se opõem ao fluxo da vida cotidiana"19. O estranhamento aos momentos ou objetos ordinários seria, assim, uma das formas de experimentação estética. Para Karina Dias, a experiência se desenvolve por uma "aspiração paisagística"20 produzida "entre olhar e o espaço cotidiano"21:

Nada mais banal para os habitantes da cidade do que subir ou descer a rua, nada mais

\footnotetext{
16 BARTHES, 2015, p. 17.

17 GUMBRECHT, 2007, p. 54

18 Ibid.

19 Ibid.

20 Cf. DIAS, 2010, p. 147

21 lbid.
} 
rotineiro no corre-corre cotidiano que as várias vistas vislumbradas dos carros, ônibus ou metrôs. No entanto, é nessa absoluta banalidade que residiriam os instantes de paisagem. Capturá-los e mostrá-los em trabalhos artísticos seria como (re)ver, ver uma vez mais o que já teria sido tantas vezes (re)visto. Uma espécie de tautologia poética em que, pela constatação, a evidência nos é mostrada de tal forma que somos conduzidos a ver (in)comum. ${ }^{22}$

O trabalho da artista visual Luiza Baldan, promove um encontro com o olhar que "ajanela o cotidiano"23 e que o transmuta em, no que denomino, recorte-paisagem urbana. A fotografia de Baldan (figura 3), a qual faz parte da série intitulada "Lagos", apresenta um desfoque que projeta o espaço em profundidade, e o turva como uma lente míope que é forçada a enxergar a distância, mas que não detecta imperfeições, que totaliza o espaço em uma só visada. Uma escada com carpete vermelho, provavelmente de um hotel, um lugar de passagem, é apresentada pela artista como paisagem em essência, com horizonte e destino incertos.

No texto curatorial para a exposição coletiva “Lugar Nenhum”, realizada no Instituto Moreira Salles do Rio de Janeiro, na qual foi exposta a obra da artista, Lorenzo Mammì e Heloisa Espada reforçam a ideia sobre a experimentação estética de quem vê, seja artista ou observador:

Em grande parte da fotografia recente, ao contrário, a experiência do mundo não se dá pela imagem, mas na imagem, como se o mundo fosse uma coleção e uma superposição infinita de imagens, cada uma remetendo a uma série potencialmente infinita de outras imagens. Não se trata necessariamente de formalismo, porque a referência a esse conjunto ilimitado de imagens não segrega da experiência do mundo; ela é, justamente, grande parte da experiência do mundo. Mas de um mundo sem fundo, queda livre de uma imagem a outra, sem que nunca possamos dizer que chegamos, não digo a um objeto, mas à reprodução fiel de nossa experiência imediata do objeto. ${ }^{24}$

Em relação à própria experiência do mundo, a efetuação de espaços sugerida por Certeau não se limita à criação de novos percursos. Afinal, como perceberíamos as possibilidades espaciais com um olhar tão condicionado que, por vezes, nos assusta ao ponto de dirigirmos um carro até um determinado destino sem entender como lá chegamos. Estar atento ao caminho e ao que se acha à sua volta abre fissuras para o acontecimento estético como relatado por Dias:

Ceralmente, quando sou interpelada por um detalhe inesperado no espaço cotidiano, a cidade se eleva diante dos meus olhos. Uma janela se abre, tudo parece diferente, o mesmo já é outro e o caminho de sempre ganha outro contorno. Esses instantes inesperados

\footnotetext{
22 Ibid.

23 Ibid, p. 145.

24 MAMİ e ESPADA, 2013.
} 
e fugidios trazem o arrebatamento porque somos travessados por aquilo que olhamos, tocados pelo espaço que nos envolve ${ }^{25}$.

Quando o detal he inesperado está nos presenteando dia após dia e num instante ele grita, pensamos em como nunca o havíamos notado. A fotografia que compõe a série "Conhecidos de Vista" (figura 4), de Letícia Lampert, artista visual e design, navega nesta linha de elaboração. Nela vemos a imagem de um cômodo de apartamento, provavelmente uma sala, na qual a janela ao fundo expõe outras habitações. O território da imagem, o cômodo, está invadido por outros espaços habitacionais. A imagem nos lança em um movimento pendular que projeta nosso olhar voyeurístico, ao tempo em que nos alarma sobre a invasão do outro. Nós os vemos e eles nos veem. Ao mesmo tempo, as habitações alheias compõem a paisagem intimista da fotografia. Lampert, em uma leitura aguçada do espaço urbano, atenta para o quanto locais, a priori íntimos, são, na verdade, compartilhados fora do círculo doméstico e partilha desta impressão com o observador.

Em todos os trabalhos apresentados a deriva advinda do íntimo é explicitada nas imagens. São olhares e convocações a espaços particularizados pelos fotógrafos, os quais cingem a intimidade consciente de cada um. Entretanto, ao observar estas imagens, justamente por sua simplicidade temática, ou por ser recorte não tradicional - em um sentido mais relacionado ao apuro técnico ou estético declarado - ou ainda, por deslocarem espaços tão familiares, me deixo afetar.

Sendo uma das principais linguagens adotadas na arte contemporânea, a fotografia reencontrou-se com o documento, deslocando espacialidades percorridas, vistas e agenciadas pelo olhar fotográfico, sem deixar de suscitar questões e provocações ao observador.

25 DIAS, 2010, p. 147. 


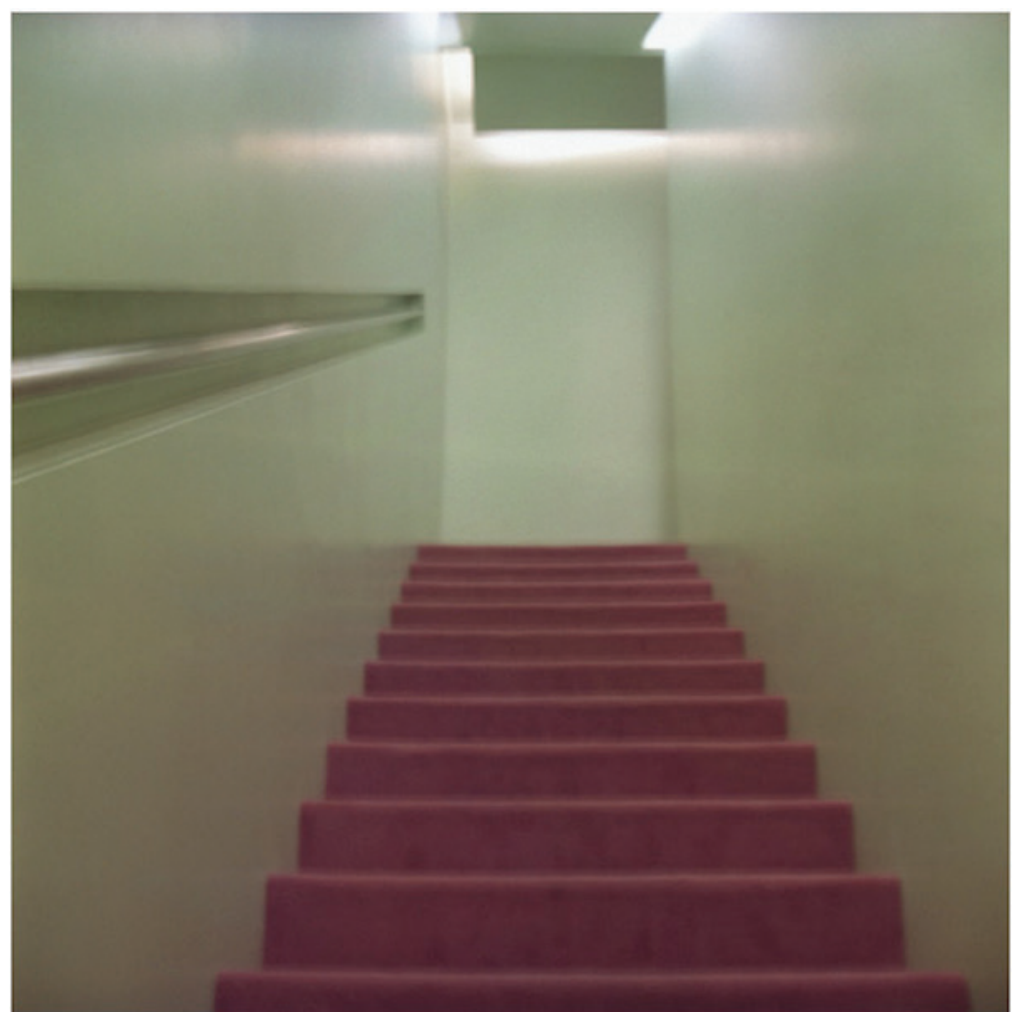

[Figura 3] Luíza Baldan. Diário urbano, 2004-2012.

Impressão a jato de tinta em papel algodão. $45 \times 60 \mathrm{~cm}$. Disponível em: https://www. luizabaldan.com/projetos/diario-urbano/Acesso em: 20/06/2019.

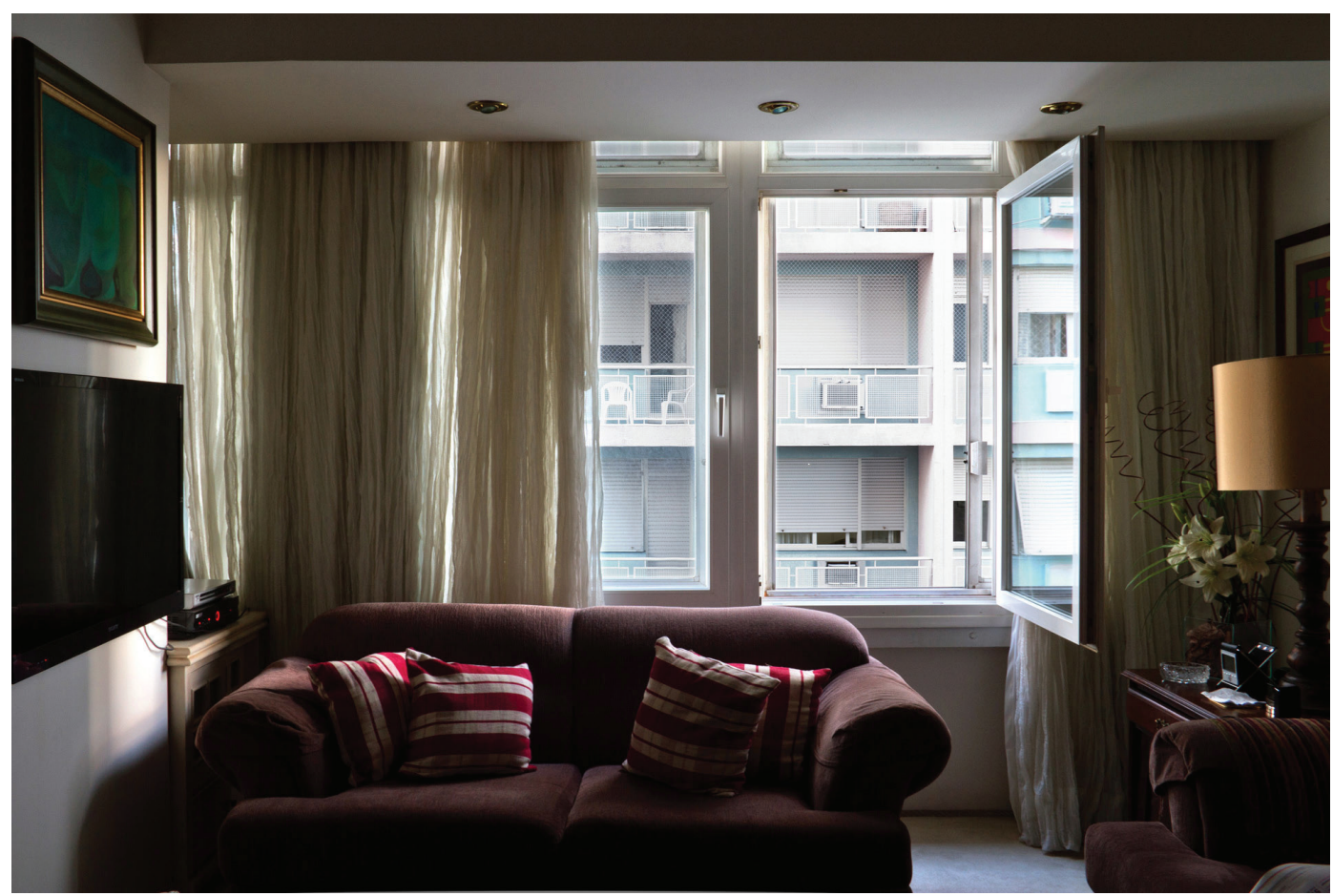

[Figura 4] Conhecidos de vista, 2013. Letícia Lampert.

Disponível em: http://www.leticialampert.com.br/home-2/art/conhecidos-de-vista/ Acesso: 20/06/2019. 


\section{Referências Bibliográficas}

AUGÉ, M. Não-lugares: Introdução a uma antropologia da super modernidade. Tradução de Maria Lucia Pereira. Campinas: Editora Papirus, 1994.

BARTHES, R. A Câmara Clara. Rio de Janeiro: Editora Nova Fronteira, v. Coleção 50 anos, 2015.

BENJAMIN, W. Pequena história da fotografia. In: Magia e técnica, arte e política. Tradução de Sergio Paulo Rouanet. $7^{\text {a }}$. ed. São Paulo: Editora Brasiliense, v. 1 Obras escolhidas., 1994.

CERTEAU, M. D. A invenção do cotidiano - artes de fazer. 3a Edição. ed. Petrópolis: Editora Vozes, 1998.

COTTON, C. A fotografia como arte contemporânea. 2a. ed. São Paulo: WMF Martins Fontes, 2013. 256 p.

DELEUZE, G.; GUATTARI, F. Mil platôs - capitalismo e esquizofrenia. Tradução de Janice Caiafa e Peter Pál Pelbart. $1 a$. ed. São Paulo: Editora 34, v. vol. 5, 1997.

DIAS, K. Entre visão e invisão: paisagem : por uma experiência da paisagem no cotidiano. 1a. ed. Brasília: Universidade de Brasília, 2010. 300 p.

DIDI-HUBERMAN, G. imagens-ocasiões. Tradução de Guilherme Ivo. $1^{\text {a }}$ Edição. ed. São Paulo: Fotô Imagem e Arte Ltda., 2018. 144 p. Os textos da obra foram traduzidos em língua portuguesa a partir de "Images-Occasions", parte integrante de "Aperçues" de Georges Didi-Huberman.

DUBOIS, P. A arte é (tornou-se) fotográfica. In:

0 ato fotográfico e outros ensaios. Tradução de Marina Appenzeller. ${ }^{\text {a }}$. ed. Campinas: Editora Papirus, 1998.

ENTLER, R. Fotografia contemporânea: entre olhares diretos e pensamentos obtusos. Revista de Comunicação da FAAP, São Paulo, v. n. 23 2011. 63-75.

A fotografia e o desejo de happening. Icônica, 15 setembro 2015. Disponivel em: <http://www.iconica.com.br/ site/a-fotografia-e-o-desejo-de-happening/>. Acesso em: 23 maio 2019.

GUMBRECHT, H. U. Pequenas crises: experiência estética nos mundos cotidianos. In: GUIMARAES, C.; LEAL, B. S.; MENDONÇA, C. C. Comunicação e experiência estética. 1a. ed. Belo Horizonte: UFMG, 2007. p. 208.

MAMİ, L.; ESPADA, H. As imagens de Passaic. Luiza Baldan, 2013. Disponivel em: <http://files.luizabaldan.com/Texto-LugarNenhum.pdf>. Acesso em: 23 maio 2019. Texto curatoria da exposição "Lugar Nenhum" realizada no Instituo Moreira Sales da Cidade do Rio de Janeiro durante 02/03 a 02/06 de 2013.

ROUILLÉ, A. Da arte dos fotógrafos à fotografia dos artistas. Revista do Patrimônio Histórico Artístico Nacional, Brasília, v. n. 27, 1998. 303-311.

SONTAC, S. Sobre fotografia. Tradução de Rubens Figueredo. Kindle. ed. São Paulo: Companhia das Letras, 2004. 224 p. Paginação irregular. 